Organization Studies

\title{
Temporary Organizing: Promises, Processes, Problems
}

\section{Rene M. Bakker}

Indiana University, USA

\section{Robert J. DeFillippi}

Suffolk University, Boston, USA

\section{Andreas Schwab}

lowa State University, USA

\section{Jörg Sydow}

Freie Universität Berlin, Germany

\begin{abstract}
Temporary organizing is introduced as process, form and perspective. Then key challenges and opportunities in the study of temporary organizing are discussed, including methodological issues, how to theorize time, and how to relate the temporary to the more permanent. This introductory article concludes with an overview of the special issue.
\end{abstract}

\section{Keywords}

project management, project networks, project-based organization, temporary employment, temporary organization

\section{Introduction}

Today's turbulent environment is heralding an increase in organizing in flexible, ad-hoc manners that involve frequent adaptations to opportunities and changes. Research has documented a concomitant rise of temporary organizing principles in and across firms (Bakker, 2010) - ranging from managing short-term projects (Sydow, Lindqvist, \& DeFillippi, 2004) and forming temporary organizations (Kenis, Janowicz-Panjaitan, \& Cambré, 2009), through to navigating short-term networks (March, 
1995), orchestrating field-configuring events (Lampel \& Meyer, 2008), maintaining temporary clusters (Maskell, Bathelt, \& Malmberg, 2006), and hiring temporary contract workers (Kalleberg, 2000). This editorial bundles, investigates, and expands the current frontiers of "temporary organizing" research and highlights how temporary organizing interacts with more permanent organization, networks, and fields.

Temporary organizing captures the activities and practices associated with collectives of interdependent individual or corporate actors who pursue ex ante agreed-upon task objectives within a predetermined time frame (see Burke \& Morley, 2016; Goodman \& Goodman, 1976; Lundin \& Söderholm, 1995). The temporality of these activities is directly tied to the expectation that this collaboration will terminate as agreed. This "institutionalized termination" (Lundin \& Söderholm, 1995 , p. 445) separates temporary organizing not only from mainstream organizational theory that is primarily concerned with open-ended organizational settings, but also from Mintzberg's (1979) adhocracy, which does not capture temporariness as the unique and constitutive feature of temporary organizing (Burke \& Morley, 2016). Notwithstanding the importance of intentionally finite time spans for temporary organizing, the actual duration of temporary organizational practices and forms may not only vary between short- and long-term but also, as many practical cases illustrate, deviate significantly from the agreement reached ex ante.

The purpose of this editorial is three-fold. First, we set the stage for this special issue. We will offer an integrative overview of different emerging perspectives in the temporary organizing literature, of the different forms that temporary organizing takes, and of the various outcomes it can produce. We feel this is warranted given the plethora of theoretical perspectives, conceptualizations, and empirical findings that have emerged in the academic literature over the last decade or so. In so doing, our deliberate focus is on temporary organizing - reflecting our explicit focus on activities and processes, and not just related organizational structures and forms (Lundin \& Söderholm, 1995). We chose this focus because we believe that the emergent, less developed nature of organizational structures in temporary systems shifts the balance from a need to understand the impact of formal structure, toward a need to understand the impact of activities and processes.

Second, we point to key opportunities and challenges in the study of temporary organizing. New temporary organizational forms continue to emerge, their prevalence and importance is increasing, and they offer important opportunities to study time and temporality. Hence, temporary organizing warrants and deserves more systematic and deeper conceptual and empirical investigation. Building on the progress made in this field of research, we will develop an overview and agenda of key research opportunities and challenges.

Finally, we summarize and introduce the set of papers included in this special issue. We will discuss not only their contribution to a theory of temporary organizing but also how they address the methodological challenges of more time-sensitive research.

\section{Temporary Organizing: Process, Form, Perspective}

What temporary organizing is (or should be) has been the topic of significant discussion over the past years. Taking a bird's eye view of recent developments in this literature, we see three main approaches toward temporary organizing that researchers have adopted: temporary organizing as process; temporary organization as form; and temporary organizing as a perspective.

\section{Temporary organizing as process}

The process perspective on temporary organizing typically puts temporality or, more precisely, temporariness center stage, and explicitly captures and conceptualizes the dynamics of change. 
This perspective has been applied to any level of analysis: from the project work of an individual manager and his or her distinctive time orientations, to the configuration of an entire organizational field (Grabher, 2004; Lampel, Lant, \& Shamsie, 2000; Lampel \& Meyer, 2008). In this view, temporary organizing encompasses the interplay of structure and agency as a duality (i.e., as "structuration") rather than a dualism (Giddens, 1984). In consequence, researchers viewing temporary organizing as a process tend to define temporary organizing as reflexive structuration that makes use of temporariness either with regard to structure (e.g., temporary task, temporary allocation of resources) or agency (e.g., temporary employment, contract work), or both. The outcomes of this process are extremely diverse, ranging from projects (as the perhaps most well-known form of temporary organization) to hiring temporary workers to complete specific tasks.

In order to distinguish and typify possible patterns and outcomes of temporary organizing in more detail, we need a more fine-grained conceptualization of the temporary organizing process (Sydow et al., 2004). Conceiving temporary organizing as a process of reflexive structuration assumes that individuals and collective agents have the capabilities to reflexively monitor not only the process and practices but also its antecedents and outcomes. Despite such capabilities for reflexive monitoring and related intentional actions, however, agents cannot completely control the process; rather, following Giddens (1984), some conditions of actions will always remain unknown and unintended consequences may feed with or without recognition into conditions of the next sequence of actions. These process characteristics constrain any reflexive structuration opportunities. The more dynamic the temporary organizing process, the more likely are unanticipated developments and outcomes. Nevertheless, temporary organizing aims at reflexive structuration using rules, routines and resources to coordinate, enable and restrain the actions of actors, both inside and outside the focal entity.

\section{Temporary organizing as form}

A second prominent perspective in the literature views temporary organizing mainly as form (e.g., Lundin \& Söderholm, 1995). This perspective focuses on the temporary organizations that the process of temporary organizing creates, i.e., formal organizations or other types of social system (e.g. temporary alliances) that are designed to disintegrate within a predetermined time frame. In the case of "project enterprises" the disintegration of this organizational entity is tied to the completion of a specific task within a given time frame. An illustrative example is a company founded to produce a specific film (DeFillippi \& Arthur, 1998) with the help of inter-organizational projects (IOP). Close to such enterprises are "ephemeral organizations" (Lanzerra, 1983), which emerge in the face of disasters, in the form of complementing rescue and relief organizations, and then disappear. These organizations may not have a single fixed date of disbanding, but the internal and external relationships of these organizations explicitly or implicitly imply their short-term nature. These organizational forms resemble the idea of a "disposable organization" (March, 1995) that aims at high short-term efficiency but only modest adaptability.

In many cases, however, researchers taking the perspective of temporary organization as form tend to define and apply notions of temporary organizing and organizational forms more broadly (e.g., Kenis et al., 2009; Lundin et al., 2015). Such studies often focus on actors establishing, maintaining, and discontinuing temporary structures such as projects or events in more permanent systems like organizations, inter-organizational networks or fields; i.e., structures that await to be enacted, reproduced or transformed by individual or collective agents participating in such projects or events. Typically the outcome of such efforts are hybrids containing a mix of temporary and permanent structures. Well-known hybrids are project-supported organizations (PSOs) as permanent organizations supported by temporary systems; project-based organization (PBOs) whose 
Table I. A typology of temporary organizing as form.

\begin{tabular}{lll}
\hline StructurelActor & Temporary & Permanent \\
\hline Temporary & (1) $\begin{array}{l}\text { Temporary, ephemeral or } \\
\text { disposable organization }\end{array}$ & (2) $\begin{array}{l}\text { Semi-temporary organization } \\
\text { (PSO, PBO, PNW) }\end{array}$ \\
Permanent & (3) $\begin{array}{l}\text { Semi-permanent organization } \\
\text { with temporary employment }\end{array}$ & (4) Permanent organization \\
\hline
\end{tabular}

business is mainly carried out in projects; and project networks (PNWs) which are created and sustained by a series of projects embedded in networks of relationships (Lundin et al., 2015). Another example of a system combining temporary and permanent forms of organizing is the project management office (PMO), typically installed in organizations that run portfolios of projects in order to enhance across-project learning (Hobbs, Aubry, \& Thullier, 2008). In addition to these, there are other, more actor- rather than structure-centered types of temporary organizing, such as part-time employment and use of independent contractors, working temporarily with intermediary organizations (such as a broker, venture capitalist or temporary work agency), engaging in transient customer or supplier relations, setting up accelerator or incubator programs, or orchestrating field-configuring events.

We believe these various forms of temporary organizing can be integrated in a typology, depicted in Table 1. This typology rests on the notion that organizational forms differ not only in their degree of temporariness, but also on whether temporariness is orchestrated dominantly by either agents or structures. In our view, only the classic permanent organizational form (quadrant 4) is typically not related to temporary organizing efforts. The other three archetypes are all possible outcomes of temporary organizing: (1) temporary, ephemeral or "disposable" organizations, delineated above as a temporary organization in a narrow sense; (2) semi-temporary organizations which capture projects and events within more permanent organizations (as in the case of PSOs and PBOs) and inter-organizational networks (as in the case of PNWs); and (3) semi-permanent organizations that strongly depend on temporary employment or contract work. While the temporariness of structure, dominant in (1) and (2), is typically attributed to organizing practices, temporary employment and contract work (3) result from staffing practices that are usually considered as part of human resource management. Both organizing and human resource management practices emphasizing the temporary often work together and produce the flexibility which a turbulent business environment can require.

The temporary, ephemeral or disposable organization (cell 1) can take many forms other than those already mentioned above. For example, it can appear as an inter-organizational arrangement, i.e., an "inter-organizational project" (Jones \& Lichtenstein, 2008), "project network" (Hellgren \& Stjernberg, 1995) or "temporary alliance" (Bakker \& Knoben, 2015) in which individuals or organizations come together for a limited time and confined task. Reflecting the focus on the embeddedness of such temporary inter-organizational arrangements in more stable networks, the notion of "latent organization" (Starkey, Barnatt, \& Tempest, 2000) and "flexible specialization" (Christopherson \& Storper, 1989; Storper, 1989) have gained some prominence in the management literature.

\section{Temporary organizing as perspective}

A third way in which researchers have viewed temporary organizing is as a perspective. Research taking this view considers temporary organizing as a fundamentally different "logic of organizing" (Powell, Koput, \& Smith-Doerr, 1996, p. 197) with high prevalence and impact for the 
understanding of organizations. Related research attempts have developed theories of temporary organizing to explain why temporary organizations exist, in what respects they differ, and how they are produced, reproduced and transformed. Taking projects as the most popular form of temporary organizing, we see research having evolved from a focus on optimization and "success factors," to later adopting contingency and comparative perspectives, hence over time having become increasingly behavioral, processual, multilevel, and relational (Söderlund, 2011).

Related to this trend, research that studies temporary organizing as perspective has adopted and developed different theoretical lenses. One such lens connects back to the process perspective discussed above. Pursuant to a recent debate in organization studies more broadly (e.g., Tsoukas \& Chia, 2002), research has contrasted the classic being ontology with the emergent becoming perspective. The latter is based upon the process philosophies of Whitehead, Bergson and Deleuze (Rescher, 1996) and makes stability rather than change the explanandum. We believe such a strong process view (Langley, Smallman, Tsoukas, \& Van de Ven, 2013; Tsoukas, 2005) on temporary organizing as process and temporary organizations as form could complement former, more moderate process studies in this special issue and in the field, which, as a whole, could profit from "process pluralism." By building on either process philosophies or social theories that emphasize process (Floricel, Bonneau, Audry, \& Sergi, 2014) such process research could go well beyond present behavioral, processual, and relational views present in project studies and satisfy the need for a stronger theoretical base of temporary organizing (Bechky \& Okhuysen, 2011; Burke \& Morley, 2016). Practice and institutional perspectives that advocate a process perspective have recently been adopted in several project studies (see Lundin et al., 2015, pp. 225-230).

\section{Key Challenges and Opportunities in the Study of Temporary Organizing}

Despite the progress that has been made by the field, there are still a number of vexing challenges in studying temporary organizing. In our view, these are three-fold: (1) how to theorize and deal with time and temporality; (2) how to explore what is "permanent" and what is "temporary" and how these interact; and (3) how to empirically study temporary organizing. At the same time, these challenges represent opportunities for improved future research on temporary organizing.

\section{How to theorize and deal with time}

The central role of time and temporality that we have frequently alluded to means that studies of temporary organizing need to take time and temporality seriously. Doing so has important theoretical as well as empirical implications.

Theoretically, it means that time becomes the central variable of interest and is no longer treated as "just" a control variable or boundary condition (George \& Jones, 2000; Langley et al., 2013). For example, next to considering the configuration of a project network at the time of formation, a temporary system can evolve as projects progress through various phases of development, a process also conceptualized as a "collaborative path" (Manning \& Sydow, 2011) or referred to as "reconfiguration" (Bakker, 2016). Initial work on temporary organizing, however, while acknowledging how central the time dimension is, has not fully captured issues of temporality such as tempo, acceleration and deceleration, rhythm, or entrainment (Grzymala-Busse, 2011; Orlikowski,\& Yates, 2002). This, however, would be important for a better understanding of temporary organizing as process, form, and perspective. Hence we believe that there is a real need for the development of conceptual models that outline the impact of time across different types of temporary organizing forms, temporary organizing tasks, and temporary organizing levels of analysis. This 
would be indispensable, in our view, for the study of temporary organizing to have a broader impact upon the studies of organizations.

Empirically, a focus on time and temporality calls for longitudinal research designs. While the temporary organizing literature is richly endowed with longitudinal single case studies, longitudinal across-project case studies, multilevel studies, and longitudinal quantitative studies are rare. Yet such data are imperative for capturing how projects or temporary organizations reconfigure and develop over time (Bakker, 2016; Schwab \& Miner, 2008). Hence, there is a continuing need for qualitative studies based on repeated interviews, field observations, or ethnographies (e.g., Bechky, 2006; see Ligthart, Oerlemans, \& Noorderhaven, 2016, as well as Swärd, 2016, in this special issue) and quantitative studies based on primary or archival data (e.g., Schwab \& Miner, 2008), and mixed-methods studies based on combining qualitative and quantitative investigations. We will further develop these ideas below.

\section{How to explore and relate what is "permanent" and what is "temporary"}

In temporary organizing what is "permanent" and what is "temporary" are sometimes fuzzy and often intertwined. In fact, the dominant current perspective on temporary organizing is that it should be understood in the relative context of the more permanent organizational structures, institutions, and networks in which it is embedded (Bakker, 2010; Burke \& Morley, 2016; Grabher, 2004; Manning \& Sydow, 2011; Schwab \& Miner, 2008). In order to address the resulting tensions between more "permanent" elements and more "temporary" ones, they first need to be clearly defined and distinguished. As already indicated, it is important to note that temporary does not mean "short duration." In the end, what is short and what is long is rather arbitrary and contextdependent (i.e., the corresponding threshold remains unclear), and any brief organizational endeavor, be it by design or by chance, could fall under the "temporary organization" label that way. Instead, temporary in our view should refer to predetermined duration, i.e., whether at the outset the time boundaries of an organizational process or venture are explicitly set (Bakker, Boros, Kenis, \& Oerlemans, 2013; Bakker \& Knoben, 2015; Burke \& Morley, 2016). In contrast, "permanent" in this view is understood as "indeterminate" - that is, open-ended with regard to time horizon. Also, in this case, the notion of permanency is tied to intentions.

What is more, temporariness has important implication for the behavior of individual and collective agents within social systems. For example, the possibility of not delivering the project on time is likely to be sanctioned by internal or external stakeholders with reference to either formal contracts or informal norms - with immediate implications for the development of the project culture or climate, the uncertainty and urgency of action, and project participants' wellbeing. Since a temporary system is often embedded in more permanent ones like organizations, networks or fields, the tensions, contradictions and synergies emerging at the interfaces between the temporary and the permanent are not yet well understood; despite early contributions in Sahlin-Andersson and Söderholm (2002) and the study of sequential film projects by Stjerne and Svejenova (2016) in this special issue. The distinction between actors and structures as carriers of temporariness, put forward in our typology (see Figure 1), could be helpful for a more differentiated understanding of the respective relationship between the temporary and the (more) permanent.

\section{How to empirically study temporary organizing}

The problems and opportunities put forth in our discussion so far culminate in a number of unique research design challenges that empirical investigations of temporary organizing face. For example, if objects of investigation only exist for a short time, researchers often need to collect data 
rapidly within short time windows and retrospective collection of additional information is often not feasible. The emergent nature of many temporary systems implies that their exact characteristics are less well known in advance, which can create challenges for research design and execution. For example, identifying and scheduling interviews with organizational members in advance is difficult before the organization has selected them. If projects face substantial deadline pressures, respondents' availability for interviews is limited. The often emergent nature of projects limits the lead time for obtaining permissions and arranging of ethnographies. In addition, any features or characteristics of temporary entities observed during early stages can still change during later stages. And the same characteristics observed during later stages may say very little about characteristics during earlier stages. More dynamic temporary organizing activities require more finegrained longitudinal capturing of these activities.

Temporary organizing, however, also has unique features that help address certain challenges to internal validity and, if exploited, enable stronger research designs. Temporary organizational activities, for example, tend to have a clear beginning and end. This characteristic facilitates capturing project-level organizing activities in their entirety, from start to finish (Grzymala-Busse, 2011). At the higher analytical level of project networks (Manning \& Sydow, 2011) and project ecologies (Grabher, 2004), projects offer unique opportunities to capture long-term network evolution based on the frequently repeated cycles of temporary organizing activities within relatively short time periods (Ahuja, Soda, \& Zaheer, 2012; Majchrzak, Jarvenpaa, \& Bagherzadeh, 2015). For example, studies of Facebook application projects, which tend to last for just a few months, allow the investigation of repeated collaboration patterns based on information from a few years, while similar investigations of more long-term collaborations, such as R\&D projects in the pharmaceutical industry, would require decades of data. These shorter time periods are often crucial to rule out alternative explanations and noise in the data related to uncaptured changes over time. Hence, temporality of activities not only creates challenges, it also implies opportunities for research design.

For one, the investigation of temporary activities tends to change - not erase - the nature of left- and right-censoring concerns. On account of having a clear beginning, any emergence of a temporary organization implies that this entity's prior history (in the narrow sense) is irrelevant as an alternative explanation for any observed patterns because it simply has no history. However, events and conditions before the creation of this entity can still affect the creation process and any subsequently observed empirical patterns. Ligthart and colleagues (2016) in this special issue offer a detailed example of how the shadow of the past affects subsequent temporary organizing. Hence, left-censoring concerns change but remain relevant, and constitute an interesting opportunity for study in the domain of temporary organizing. Similarly, the expected disintegration of the organizational entity can reduce its shadow of the future (see Swärd, 2016, in this special issue). Again, this only changes the nature of potential right-censoring concerns, and does not alleviate them completely. For example, project participants may be highly concerned about developing relationships with potential future collaborators in order to secure future employment. The expected disintegration of temporary systems is likely to raise the level of these concerns and the relevance of the related shadow of the future. The anticipation of these future events again has the potential to affect how temporary organizing unfolds. Hence, in a temporary organizing context right-censoring issues remain relevant, but in a different way than usual-again offering opportunities for novel research designs.

Most popular methodologies. The majority of submissions to and most of the papers accepted for this special issue were qualitative case studies of various kinds. Case studies represent a highly flexible methodology, which can offer some advantages when investigating emergent and dynamic 
empirical settings. Typically, researchers use case studies to develop theory inductively for research questions more or less tightly scoped within an existing theory (Eisenhardt \& Graebner, 2007). The upfront integration into established theory helps justify the importance of the investigated research questions and the promise of the qualitative data from the identified case to address this research question. In contrast, purely phenomenon-driven research questions, as promoted by some grounded theory approaches, are extremely rare.

The selection of cases indicates a propensity to study high attention events, such as Olympic Games, Hollywood movies or large public construction projects (see van Marrewijk, Ybema, Smits, Clegg, \& Pitsis, 2016, and Swärd, 2016, in this special issue). Related salience-based case selection biases imply opportunities to study temporary organizing in potentially equally important, but more mundane and potentially more hidden, empirical contexts as well as under-studied international contexts. For example, the paper by Prado and Sapsed (2016) published in this special issue examines a specific cultural context (Brazil) and its cultural impact on adoption and adaptation of past project innovations on future innovations within a large Brazilian company.

We believe that beyond expanding the range of empirical settings, there are also opportunities for researchers to expand the range of applied methodologies and research designs. The following areas of recent methodological advances warrant the attention of temporary organizing researchers in our view: comparative case studies (Eisenhardt \& Graebner, 2007), process research methodologies (Langley et al., 2013; Van de Ven \& Poole, 2005), advanced multilevel modeling (Moliterno \& Mahony, 2011; Rabe-Hesketh \& Skrondal, 2008), and mixed-method designs (Greene, Caracelli, $\&$ Graham, 1989; Morgan, 1998).

Comparative case studies. As indicated above, case studies remain a dominant research methodology for investigations of temporary organizing. They can enable the highly flexible collection of rich data capturing dynamic change processes (Langley et al., 2013). So far, however, researchers have only started to exploit recent advances in case study methodology focused on comparative multiple-case study designs. Evidence from multiple cases is generally more robust, generalizable, and testable compared to single case study findings (Eisenhardt \& Graebner, 2007). Researchers can further enhance these positive effects by carefully creating portfolios of cases that enable replications, contrasts, boundary tests, and ruling out alternative explanations (Yin, 1994). Hence, we feel that researchers should combine data access considerations with careful theoretical sampling. Multiple case studies imply substantially larger research projects, but they promise a much deeper interpretation and understanding of the investigated phenomena. Surprisingly, theories generated from multiple case study designs are often more parsimonious because multiple cases provide better safeguards to prevent researchers from developing propositions based on idiosyncrasies of single cases. Hence, relationships that replicate across multiple cases are likely more robust and generalizable.

Prado and Sapsed (2016) in this special issue illustrate the use of comparative cases nested within a single case organization setting. Similarly, Stjerne and Svejenova (2016), also in this special issue, employ comparative case studies of sequential film projects to understand the relationship between these temporary project organizations and their common film project sponsor. Such nested studies enrich our understanding of the contexts in which these projects are comparatively examined.

Process studies. Temporary organizing activities are inherently dynamic. Any stability is constantly challenged (Farjoun, 2010), and merely represents judgments of relatively lower rates of change by observers which are the result of ongoing processes that eventually lead to replications 
of prior process outcomes, but these replications are never perfect (Giddens, 1984; Rescher, 1996). Consequently, temporary organizing views organizational phenomena as inherently dynamic processes, which implies a lower fit for traditional research methodologies focused on capturing and comparing more stable organizational characteristics and grounded in perspectives that view organizations as relatively stable configurations of resources and routines (Langley 2009; Van de Ven \& Poole, 2005).

In contrast, process research methodologies, no matter whether adopting a moderate or strong process view, are designed to capture and explain how sequences of events and activities unfold over time and produce specific outcomes, including the form of the temporary organization in its narrow or broader sense. Process study methodologies investigate phenomena dynamically by explicitly capturing and considering the implications of movements, change activities, as well as temporal evolution of events. Beyond empirical investigations, simulations using agent-based models represent another option to explore the implications of dynamic processes (Miller, 2015). Obviously, time-series, event-history, and simulation methodologies enable quantitative investigation of such dynamic processes; however, they typically involve "a rather coarse-grained outcropping of events and variables over time: they skim the surface of processes rather than plunging into them directly" (Langley, 1999, p. 705). As such, these methodologies are limited to a moderate process perspective on temporary organizing. Case studies using narrative, interpretative, and qualitative data again represent powerful alternative approaches and therefore are most useful from a strong process perspective (Langley et al., 2013). In any case, high-quality case studies-like those included in this special issue-require substantial time and effort, as well as well-trained research teams. If done right, they have the capacity to unveil the processes and activities that shape temporary systems and their outcomes. An excellent example is the study of inter-organizational projects in the Dutch shipbuilding industry in this special issue by Ligthart and colleagues (2016), whose results point to the roles of the shadow of the past and the shadow of the future in explaining flexibility behaviors between participants.

Advanced multilevel modeling. In the case of embedded temporary organizing, empirical investigations may require methodologically complex approaches to capture relevant events and activities on multiple levels, and relationships between these activities (Mathieu \& Chen, 2011). Empirical research of interdependent processes taking place simultaneously at different levels of analysislike projects, networks and fields - creates unique challenges for quantitative investigations given the nested nature of observations (Aguinis, Boyd, Pierce, \& Short, 2011). If multilevel phenomena are not properly acknowledged and modeled, this has two negative consequences (Aguinis \& Edwards, 2014). First, covariation of variables across levels can lead to gross errors of prediction when using techniques, such as OLS, that rely on error independence. Resulting standard errors tend to be biased downwardly. Second, researchers miss opportunities to identify cross-level direct effects and cross-level interaction effects (Aguinis \& Culpepper, 2015). Again, the resulting underspecified models imply potential errors in prediction.

Recent advances in statistical modeling specifically focused on multilevel data offer new opportunities to address these challenges (Rabe-Hesketh \& Skrondal, 2008). These methods include hierarchical linear modeling, multilevel structural equation modeling (Preacher, Zyphur, \& Zhang, 2010), within-and-between analysis, interdependency analysis and others (Klein \& Koslowski, 2000). These emerging techniques obviously have their unique strengths and limitations which are currently still being discovered, but they promise new opportunities for a deeper quantitative investigation of multilevel phenomena that so far have been rarely applied by temporary-organizing researchers. 
Mixed-methods research designs. Mixed-method designs combine both quantitative and qualitative approaches in a single empirical study. Such design approaches have been used successfully to investigate multilevel phenomena in education and health science research (Greene et al., 1989; Morgan, 1998). Theory building and testing of temporary organizing is likely to benefit from studies that try to integrate and combine process-oriented and outcome-oriented research. As outlined above, process studies offer opportunities for capturing dynamic activities and change and identify underlying driving factors. They can provide indispensable input on what variables are important, how they influence outcomes, and when. Quantitative approaches in mixed-methods study enable estimations of related effect sizes and distributions across large numbers of cases and observations. At the same time, quantitative investigations can help identify cases and questions that deserve deeper qualitative investigations. Such deep integration of both qualitative and quantitative designs obviously requires substantial data collection efforts and broad methodological expertise of research teams. At the same time, these approaches promise a much deeper understanding of the inherently complex and dynamic phenomena associated with temporary organizing. In addition, the increasing availability of secondary comprehensive data, digitally recording activities and events often labeled as "big data," creates new opportunities not only for more comprehensive quantitative investigations but also for mixed-method designs.

In sum, temporary organizing research offers unique challenges and opportunities for conducting empirical research. It is our hope that readers will find the above helpful as they plan their next research study.

\section{Overview of the Special Issue}

In all, researchers submitted 80 studies for publication in this special issue. Almost two-thirds of them used qualitative methodologies; about a quarter applied quantitative methodologies, none a mixed-method approach. We also received eight conceptual papers. Through a rigorous revision process, this set was brought down to the final set of accepted papers, which provides an excellent collection of quantitative and qualitative articles that we believe will challenge and push further the frontiers of temporary organizing research.

This special issue opens with a study by Ligthart and colleagues (2016), an insightful longitudinal case study of operational flexibility behaviors within an inter-organizational project between a Dutch shipbuilding yard contractor and eight subcontractors to design and construct the shipyard's first-of-its-kind yacht-like vessel. The study's detailed observations and interviews with representatives of both the shipyard contractor and each subcontractor provide an impressive trail of evidence for its findings that operational flexibility behaviors are enabled by trust between project participants, sense of urgency, and available resources. These enablers are influenced by positive experiences in previous interactions ("shadow of the past") and expectations of possible future collaboration ("shadow of the future"), the temporary nature of inter-organizational projects and slack in project tasks, respectively. Findings from this paper may be usefully compared with the findings reported on trust by Swärd (2016), also in this special issue.

Next, Van Marrewijk and colleagues (2016) examine how project members negotiate their roles, responsibilities, and hierarchical relations in the collaboration between principal and agent contracting organizations in a large-scale global infrastructure construction project. Their qualitative study of the Panama Canal extension project draws upon a rich array of historical, observational, and interview data to examine the sources and consequences of the tensions between order and conflict in temporary organizing. They report how contractual arrangements, intercultural histories, and organizational traditions gave rise to ambiguous and potentially conflicting interests, cultural identities, and expectations between organizations participating in an international megaproject. They 
document how persistent ambiguities in the roles, responsibilities, and hierarchic relations triggered more conflict-ridden in situ negotiations over expected roles of principals and agents. Their conceptual framework focuses on social practices, as well as relational and temporal discourse, to reveal the day-to-day processes of harmonization and contestation.

Stjerne and Svejenova (2016) examine the interactions at the boundaries between a Danish film production company (a permanent organization) and a sequence of temporary organizations created by the production company for a superhero children's film and its two sequels. Their qualitative, ethnographic case study of the relationship between the permanent organization and each film project's temporary organization reveals cross-level tensions, as well as boundary work and boundary roles that address them. Their focus on a sequence of projects allows them to bring in shadows of past and future projects. The study extends our understanding of the dialectic between temporary and permanent organizing by emphasizing how ongoing work at different boundaries affects the permanent and temporary organizing's connectedness and outcomes. It also challenges the overly bracketed view of temporary organizations, suggesting instead that the shadows of the past and future experienced in earlier projects in the sequel sequence impacted the tensions, boundary work, and boundary roles created in subsequent sequel projects to address these tensions.

Prado and Sapsed (2016) offer a distinctive cultural perspective in their case study of the processes by which innovations developed in prior projects are codified within an intra-firm knowledge base and then adapted for use in future projects. They analyse innovation activities of 15 projects at Petrobras and provide evidence of a Brazilian culture-based motivational factor (anthropophagy) promoting openness to new ideas, but also a desire to consume and mimic these and thus contribute to new combined forms that depart from the so-called "economies of repetition" (Davies \& Brady, 2000; Grabher, 2004). This cultural factor coexists with an extensive firmspecific investment in subject matter expertise and processes that support utilization of a database of 1,100 previous project innovations. The study concludes that Petrobras may represent an extreme case of anthropophagy because of its considerable slack resources to support its investment in expertise and deliberative project review and dissemination processes.

Tukiainen and Granqvist (2016) examine a university transformation project (Innovation University) which they characterize as an institutional project - a temporary organization with the aim to change the rules, regulations, and beliefs within a relatively bounded institutional setting. Their inductive longitudinal case study addresses the following questions: what kind of activities do actors in an institutional project carry out; and how do these actors and activities produce institutional change? They document the unfolding of two sequential projects: the predesign project to create the project plan for Innovation University and the design project to develop the organization and practices for Innovation University and to incorporate those changes in government legislation that would charter the university. This study's unique contribution lies in its careful examination of a series of transitions: the transition of tasks from one project organization to a subsequent one; the transition of regulative texts from the temporary project organization to the more permanent legislative actors and bodies; and the transition of political power from one kind of political coalition to another. Their study elaborates how links to past and future between the sub-projects took shape through the interplay of both material objects (e.g., the project plan) and project actors.

Swärd (2016) concludes the set of qualitative papers with her longitudinal case study focusing on what kind of actions and what kinds of reciprocity are most important for the emergence of trust. The study examines how reciprocal norms at the industry level, as well as reciprocal norms developed during project execution, contribute to the emergence of trust. Her case setting is a three-year construction project whose organizational participants are a private contractor and a client, the Norwegian Public Roads Administration. This study follows the project prospectively from its initiation through to its termination. Her study findings suggest that trust interacts with 
reciprocal norms at both the industry and project level and trust development is an ongoing process in which different types of actions and different types of reciprocity play a part. Specific reciprocity (one party's action is quickly reciprocated by a similar scale of response by the other party) is important when trust is low and can substitute for trust, because it helps reduce uncertainty, thereby laying a foundation for deeper forms of trust. When trust has deepened, partners rely on diffuse reciprocity (one party's action not resulting in immediate reciprocity) on both small and large actions. Closer to project termination, however, reciprocity again becomes more specific, especially in terms of negotiation behavior, as there is a shorter time horizon for payback to occur (reflective of a limited shadow of the future).

Ebers and Maurer (2016), finally, offer a detailed empirical study of the conditions that drive members of temporary organizations to engage in recurrent partnering. We know from previous research that firms have a tendency to work together again on subsequent projects, and that doing so has several consequences, including realizing economies of repetition and inter-project knowledge transfer (e.g., Brady \& Davies, 2004). As Ebers and Maurer rightly point out, however, we know much less of the antecedents driving the tendency for recurrent partnering, and under what conditions firms do and do not choose to collaborate again after a focal project. Drawing on detailed, quantitative data on 102 construction projects in Germany, Ebers and Maurer find that a successful outcome of prior collaboration motivates project partners to continue their partnership, and that an increasing frequency of prior collaboration accentuates this positive effect. In addition, the authors identify two boundary conditions - namely, the degree of trust and relationshipspecific investments - which affect how experiences with the outcomes of prior collaboration influence expectations of future collaboration. Overall, their findings paint a fascinating picture of how experiential learning, trust, and the opportunity cost of switching partners interact to explain the likelihood of recurrent partnering.

\section{Conclusion}

The overarching goal of this opening essay, and the special issue as a whole, is to advance the understanding of temporary organizing. Temporary organizing, perhaps paradoxically, is here to stay. It is an emergent and important process, organizational form, and theoretical perspective that warrants systematic research attention. Taken as a group, the articles in this special issue chart the current state of the art in this important field of research.

We acknowledge that studying temporary organizing presents its own set of challenges. For example, studies of temporary organizing as process, including those in this special issue, so far have made almost exclusively use of moderate process perspectives such as structuration or other types of practice-based theory. This particular kind of study awaits to be challenged by stronger process views such as "the becoming" perspective (Tsoukas \& Chia, 2002), building on process philosophies of Whitehead and others (see Helin et al., 2014). However, if compared to management and organization studies more generally, even serious practice-based research has a backlog in the field of temporary organizing in general and project studies in particular (Lundin et al., 2015, pp. 225-230). This is particularly true with regard to a practice-based understanding of time that emphasizes "temporal structuring" (Orlikowski \& Yates, 2002) in which knowledgeable agents enact, reproduce or transform temporal structures such as meeting schedules, project deadlines, or reporting periods. Enacting temporal structures allows agents (which is of critical importance in temporary organizing) to "perform" time (Ballard \& Seibold, 2003), i.e., to implicitly or explicitly make sense of, regulate, coordinate, and account for their activities through the legitimized temporal structures they recurrently enact on multiple levels of analysis (Bakker, 2010). 
In addition, progress in the field of temporary organizing research will benefit from researchers investigating related phenomena using a wide variety of methodological approaches. Hence, a balanced variety of approaches is desirable, including mixed-method approaches. In spite of the indications for the value of case studies, the apparent lack of quantitative studies is likely inhibiting scientific progress. Causal propositions developed and supported in case studies should trigger deductive studies to investigate whether they replicate in broader samples and to identify their boundary conditions. Other fields of management research have experienced an increasing number of quantitative studies using archival databases and encourage researchers to engage in more timeintensive studies around qualitative data (Crook, Bratton, Street, \& Ketchen, 2006). In the field of temporary organizing, however, more deductive studies to investigate propositions identified in qualitative case studies are desirable - in spite of challenges to obtain related quantitative data.

Finally, temporary organizing challenges management practice. A recent study of temporary, emergent collaboration in the initial days following the Columbia disaster in 61 counties of the state of Texas unearthed the difficulties in developing mutual trust and collective identity under these ephemeral circumstances (Beck \& Plowman, 2014). At the same time, the authors point to the possibilities of creating swift trust and situation-based social identity. But how exactly can this be done? How can management reconcile the challenges of flexibility concerns for workers with the expectations of organizational members for more long-term and predictable employment? The papers in this special issue abound with lessons learned and their implications for management. For example, Van Marrewijk and colleagues (2016) observed the critical importance that agreements on roles, relations, and collaboration philosophy made in the tender phase of an inter-organizational project be clearly communicated to the project employees of both contractor and client organization in the execution phase. In their study of operational flexibility within an inter-organizational project, Ligthart and colleagues (2016) concluded that successful collaboration with a stable set of partners is likely to increase operational flexibility while constraining the creation and transfer of new knowledge and exploration of innovative activities. For innovation and knowledge creation, it is advantageous to seek out new and diverse partners. Swärd (2016) provides numerous practical suggestions for how managers can utilize small and large actions to build trust and reciprocity between clients and their subcontractors.

While we acknowledge challenges and the fact that much more work remains to be done, we believe this special issue presents valuable ideas, perspectives, and models for doing research on temporary organizations. We hope that readers will find that as a collection, the articles in this issue push the boundaries of this important field of research.

\section{Acknowledgements}

We wish to thank the numerous authors who submitted their papers to this Special Issue, the excellent reviewers who put a lot of effort into evaluating the manuscripts and advising the authors how to improve their papers, and - last but not least - Robin Holt, Organization Studies Editor-in-Chief, and Sophia Tzagaraki, Organization Studies Managing Editor, for supporting us very efficiently and effectively in the whole process of producing this Special Issue.

\section{Funding}

This research received no specific grant from any funding agency in the public, commercial, or not-for-profit sectors.

\section{Note}

Authors of this paper are listed in alphabetic order. 


\section{References}

Aguinis, H., Boyd, B. K., Pierce, C. A., \& Short, J. C. (2011). Walking new avenues in management research methods and theories: Bridging micro and macro domains. Journal of Management, 37, 395-403.

Aguinis, H., \& Culpepper, S. A. (2015). An expanded decision-making procedure for examining cross-level interaction effects with multilevel modeling. Organizational Research Methods, 18, 155-176.

Aguinis, H., \& Edwards, J. R. (2014). Methodological wishes for the next decade and how to make wishes come true. Journal of Management Studies, 51, 143-174.

Ahuja, G., Soda, G., \& Zaheer, A. (2012). Introduction to the special issue: The genesis and dynamics of organizational networks. Organization Science, 23, 434-448.

Bakker, R. M. (2010). Taking stock of temporary organizational forms: A systematic review and research agenda. International Journal of Management Reviews, 12, 466-486.

Bakker, R. M. (2016). Stepping in and stepping out: Strategic alliance partner reconfiguration and the unplanned termination of complex projects. Strategic Management Journal, Forthcoming. DOI: $10.1002 / \mathrm{smj} .2429$

Bakker, R. M., Boros, S., Kenis, P., \& Oerlemans, L. A. G. (2013). It's only temporary: Time frame and the dynamics of creative project teams. British Journal of Management, 24, 383-397.

Bakker, R. M., \& Knoben, J. (2015). Built to last or meant to end: Intertemporal choice in strategic alliance portfolios. Organization Science, 26, 256-276.

Ballard, D. I., \& Seibold, D. R. (2003). Communicating and organizing in time: A meso-level model of organizational temporality. Management Communication Quarterly, 16, 380-415.

Bechky, B. A. (2006). Gaffers, gofers, and grips: Role-based coordination in temporary organizations. Organization Science, 17, 3-21.

Bechky, B. A., \& Okhuysen, G. A. (2011). Expecting the unexpected? How SWAT officers and film crews handle surprises. Academy of Management Journal, 54, 239-261.

Beck, T. E., \& Plowman, D. A. (2014). Temporary, emergent interorganizational collaboration in unexpected circumstances: A study of the Columbia space shuttle response effort. Organization Science, 25, 12341252.

Brady, T., \& Davies, A. (2004). Building project capabilities: From exploratory to exploitative learning. Organization Studies, 25, 1601-1621.

Burke, C. M., \& Morley, M. J. (2016). On temporary organizations: A review, synthesis and research agenda. Human Relations, 69, 1235-1258.

Christopherson, S., \& Storper, M. (1989). The effects of flexible specialization on industrial politics and the labor market: The motion picture industry. ILR Review, 42, 331-347.

Crook, T. R., Bratton, V. K., Street, V. L., \& Ketchen Jr., D. J. (2006). Has strategic management shed the normal science straightjacket? Revisiting Bettis' (1991) critiques. Journal of Managerial Issues, 18, 409-423.

Davies, A., \& Brady, T. (2000). Organizational capabilities and learning in complex product systems: Towards repeatable solutions. Research Policy, 29, 931-953.

DeFillippi, R. J., \& Arthur, M. B. (1998). Paradox in project-based enterprise: The case of film making. California Management Review, 40, 125-139.

Ebers, M., \& Maurer, I. (2016). To continue or not to continue? Drivers of recurrent partnering in temporary organizations. Organization Studies, 37, 1861-1895.

Eisenhardt, K. M., \& Graebner, M. E. (2007). Theory building from cases: Opportunities and challenges. Academy of Management Journal, 50, 25-32.

Farjoun, M. (2010). Beyond dualism: Stability and change as a duality. Academy of Management Review, 35, 202-225.

Floricel, S., Bonneau, C., Audry, M., \& Sergi, V. (2014). Extending project management research: Insights from social theories. International Journal of Project Management, 32, 1091-1107.

George, J. M., \& Jones, G. R. (2000). The role of time in theory and theory building. Journal of Management, $26,657-684$.

Giddens, A. (1984). The constitution of society. Cambridge: Polity. 
Goodman, R. A., \& Goodman, L. P. (1976). Some management issues in temporary systems: A study of professional development and manpower-the theater case. Administrative Science Quarterly, 21, 494-501.

Grabher, G. (2004). Temporary architectures of learning: Knowledge governance in project ecologies. Organization Studies, 25, 1491-1514.

Greene, J., Caracelli, V., \& Graham, W. (1989). Toward a conceptual framework for mixed-method evaluation designs. Educational Evaluation and Policy Analysis, 11, 255-274.

Grzymala-Busse, A. (2011). Time will tell? Temporality and the analysis of causal mechanisms and processes. Comparative Political Studies, 44, 1267-1297.

Helin, J., Hernes, T., Hjorth, D., \& Holt, R. (Eds.) (2014). The Oxford handbook of process philosophy and organization studies. Oxford: Oxford University Press.

Hellgren, B., \& Stjernberg, T. (1995). Design and implementation in major investments - a project network approach. Scandinavian Journal of Management, 11, 377-394.

Hobbs, B., Aubry, M., \& Thullier, D. (2008). The project management office as an organisational innovation. International Journal of Project Management, 26, 547-555.

Jones, C., \& Lichtenstein, B. B. (2008). Temporary inter-organizational projects: How temporal and social embeddedness enhance coordination and manage uncertainty. In S. Cropper, M. Ebers, C. Huxham, \& P. S. Ring (Eds.), The Oxford handbook of inter-organizational relations (pp. 231-255). Oxford: Oxford University Press.

Kalleberg, A. L. (2000). Nonstandard employment relations: Part-time, temporary and contract work. Annual Review of Sociology, 26, 341-365.

Kenis, P., Janowicz-Panjaitan, M., \& Cambré, B. (Eds.) (2009). Temporary organizations-Prevalence, logic and effectiveness. Cheltenham, UK: Edward Elgar.

Klein, K. J., \& Koslowski, S. W. J. (2000). Multilevel theory, research, and methods in organizations: Foundations, extensions, and new directions. San Francisco, CA: Jossey-Bass.

Lampel, J., Lant, T., \& Shamsie, J. (2000). Balancing act: Learning from organizing practices in cultural industries. Organization Science, 11, 263-269.

Lampel, J., \& Meyer, A. D. (2008). Guest editors' introduction: Field-configuring events as structuring mechanisms: How conferences, ceremonies, and trade shows constitute new technologies, industries, and markets. Journal of Management Studies, 45, 1025-1035.

Langley, A. (1999). Strategies for theorizing from process data. Academy of Management Review, 24, 691710.

Langley, A. (2009). Studying processes in and around organizations. In D. A. Buchanan \& A Bryman. (Eds.), Sage handbook of organizational research methods (pp. 409-429). London: SAGE Publications.

Langley, A., Smallman, C., Tsoukas, H., \& Van de Ven, A. H. (2013). Process studies of change in organization and management: Unveiling temporality, activity, and flow. Academy of Management Journal, 56, $1-13$.

Lanzerra, G. F. (1983). Ephemeral organizations in extreme environments: Emergences, strategy, extinctions. Journal of Management Studies, 20, 71-95.

Ligthart, R., Oerlemans, L., \& Noorderhaven, N. (2016). In the shadows of time: A case study of flexibility behaviors in an interorganizational project. Organization Studies, 37, 1721-1743.

Lundin, R., Arvidsson, N., Brady, T., Eksted, E., Midler, C., \& Sydow, J. (2015). Managing and working in project society - Institutional challenges of temporary organizations. Cambridge: Cambridge University Press.

Lundin, R. A., \& Söderholm, A. (1995). A theory of the temporary organization. Scandinavian Journal of Management, 11, 437-455.

Majchrzak, A., Jarvenpaa, S. L, \& Bagherzadeh, M. (2015). A review of interorganizational collaboration dynamics. Journal of Management, 41, 1338-1360.

Manning, S., \& Sydow, J. (2011). Projects, paths, practices: Sustaining and leveraging project-based relationships. Industrial and Corporate Change, 20, 1369-1402.

March, J. G. (1995). The future, disposable organizations and the rigidities of imagination. Organization, 2, $427-440$. 
Maskell, P., Bathelt, H., \& Malmberg, A. (2006). Building global knowledge pipelines: The role of temporary clusters. European Planning Studies, 14, 997-1013.

Mathieu, J. E., \& Chen, G. (2011). The etiology of the multilevel paradigm in management research. Journal of Management, 37, 610-641.

Miller, K. D. (2015). Agent-based modeling and organization studies: A critical realist perspective. Organization Studies, 36, 175-196.

Mintzberg, H. (1979). The structuring of organizations. Englewood-Cliffs, NJ: Prentice-Hall.

Moliterno, T. P., \& Mahony, D. M. (2011). Network theory of organization: A multilevel approach. Journal of Management, 37, 443-467.

Morgan, D. (1998). Practical strategies for combining qualitative and quantitative methods: Applications to health research. Qualitative Health Research, 8, 362-376.

Orlikowski, W. J., \& Yates, J. (2002). It's about time: Temporal structuring in organizations. Organization Science, 13, 684-700.

Powell, W. W., Koput, K. W., \& Smith-Doerr, L. (1996). Interorganizational collaboration and the locus of innovation: Networks of learning in biotechnology. Administrative Science Quarterly, 41, 116-145.

Prado, P., \& Sapsed, J. (2016). The anthropophagic organization: How innovations transcend the temporary in a project-based organization. Organization Studies, 37, 1793-1818.

Preacher, K. J., Zyphur, M., \& Zhang, Z. (2010). A general multilevel SEM framework for assessing multilevel mediation. Psychological Methods, 15, 209-233.

Rabe-Hesketh, S., \& Skrondal, A. (2008). Multilevel and longitudinal modeling using Stata. College Station, TX: Stata Press.

Rescher, N. (1996). Process metaphysics: An introduction to process philosophy. Albany, NY: State University of New York Press.

Sahlin-Andersson, K., \& Söderholm, A. (Eds.) (2002). Beyond project management: New perspectives on the temporary-permanent dilemma. Malmö: Liber.

Schwab, A., \& Miner, A. S. (2008). Learning in hybrid-project systems: The effect of project performance on repeated collaboration. Academy of Management Journal, 51, 1117-1149.

Söderlund, J. (2011). Pluralism in project management: Navigating the crossroads of specialization and fragmentation. International Journal of Management Reviews, 13, 153-176.

Starkey, K., Barnatt, C., \& Tempest, S. (2000). Beyond networks and hierarchies: Latent organizations in the U.K. television industry. Organization Science, 11, 299-305.

Stjerne, I. S., \& Svejenova, S. V. (2016). Connecting temporary and permanent organizing: Tensions and boundary work in sequential film projects. Organization Studies, 37, 1771-1792.

Storper, M. (1989). The transition to flexible specialization in the U.S. film industry: External economies, the division of labour, and the crossing of industrial divides. Cambridge Journal of Economics, 13, 273-305.

Swärd, A. (2016). Trust, reciprocity, and actions: The development of trust in temporary inter-organizational relations. Organization Studies, 37, 1841-1860.

Sydow, J., Lindkvist, L., \& DeFillippi, R. J. (2004). Project-based organizations, embeddedness and repositories of knowledge: Editorial. Organization Studies, 25, 1475-1489.

Tsoukas, H. (2005). Complex knowledge: Studies in organizational epistemology. Oxford: Oxford University Press.

Tsoukas, H., \& Chia, R. (2002). On organizational becoming: Rethinking organizational change. Organization Science, 13, 567-582.

Tukiainen, S., \& Granqvist, N. (2016). Temporary organizing and institutional change. Organization Studies, 37, 1819-1840.

Van de Ven, A. H., \& Poole, M. S. (2005). Alternative approaches for studying organizational change. Organization Studies, 26, 1377-1404.

Van Marrewijk, A. H., Ybema, S., Smits, K., Clegg, S., \& Pitsis, T. S. (2016). Clash of the Titans: Temporal organizing and collaborative dynamics in the Panama Canal Megaproject. Organization Studies, 37, 1745-1769.

Yin, R. K. (1994). Case study research: Design and methods (2nd edn.). Thousand Oaks, CA: SAGE Publications. 


\section{Author biographies}

Rene Bakker is an Assistant Professor of Management and Entrepreneurship at the Kelley School of Business at Indiana University. Previously, he worked as a Research Fellow at the Australian Centre for Entrepreneurship Research in Brisbane, Australia. He received his PhD from Tilburg University in 2011. Rene studies how (small) businesses can improve their competitive positions through the formation of varying types of strategic alliances and the successful execution of temporary projects. His research has appeared in leading management journals including Academy of Management Journal, Strategic Management Journal, and Organization Science.

Robert Defillippi is Professor of Strategy and International Business at the Sawyer Business School, Suffolk University, Boston, Massachusetts, USA and is Adjunct Professor in the School of Management, Queensland University of Technology, Brisbane, Australia. He is the co-editor of the Business Innovation and Disruption in Creative Industries book series (Edward Elgar). He also serves on the editorial board of Journal of Media Business Studies and has published twelve books and over 70 academic papers and book chapters. Professor DeFillippi has published in a range of leading journals, including Academy of Management Review, California Management Review, Journal of Organizational Behavior, Organization Studies, Regional Studies, and Research Policy. His primary areas of project scholarship include project-based organizing, project networks, project learning, and project-based careers.

Andreas Schwab is an Associate Professor and Dean's Fellow in the College of Business at Iowa State University (aschwab@iastate.edu). He studies organizational learning processes in dynamic environments, such as project ventures and temporary organizations. He is also engaged in several initiatives to advance methodological practices in the management field by promoting alternatives to statistical significance tests and introducing scholars to Bayesian statistics. His research has been published in Academy of Management Journal, Organization Science, Strategic Organization, Entrepreneurship Theory \& Practice, Industrial and Corporate Change, Industrial Relations, Family Business Review, Group and Organization Management and other outlets. He is a Contributing Editor for Research Methodology and Statistics at Entrepreneurship, Theory \& Practice and serves on the editorial boards of Organization Science and Strategic Entrepreneurship Journal.

Jörg Sydow is a Professor of Management at the School of Business \& Economics at Freie Universität Berlin, Germany, and the director of the Research Unit "Organized Creativity", sponsored by the German Research Foundation (DFG). He is a founding co-editor of two leading German journals, Managementforschung and Industrielle Beziehungen - The German Journal of Industrial Relations, and a member of the editorial review boards of Organization Studies, Academy of Management Journal, Academy of Management Review, Journal of Management Studies, and The Scandinavian Journal of Management. Most recently he co-authored Managing Inter-organizational Relations (with Elke Schüßler \& Gordon Müller-Seitz), published by Palgrave Macmillan, London 2016. 